\title{
Knowledge, Beliefs, and Attitudes of Dental and Dental Hygiene Students Toward Obesity
}

\author{
Kelly R. Magliocca, D.D.S.; Marvin F. Jabero, D.D.S.; Dale L. Alto, D.D.S.; \\ Joseph F. Magliocca, M.D.
}

Abstract: Obesity is recognized as a growing public health problem. The authors surveyed dental hygiene and dental students from one institution regarding education, knowledge, perceived professional duties, and attitudes toward the overweight and obese population. Half of the respondents reported no obesity education prior to professional dental education, and 80 percent received five hours or less while in professional training. While most students held a generally positive attitude regarding obese and overweight patients, a number of students demonstrated evidence of negative stereotyping. Obesity education and training must be integrated into dental education to permit greater understanding of coexisting medical problems, explore the basis for a negative attitude and work toward its elimination, and raise public health awareness within dentistry.

Dr. Kelly Magliocca is Adjunct Clinical Assistant Professor, Department of Oral \& Maxillofacial Surgery, University of Michigan; Dr. Jabero is an Intern, Department of Oral \& Maxillofacial Surgery, The Ohio State University; Dr. Alto is a firstyear resident, Department of Oral \& Maxillofacial Surgery, University of Connecticut; and Dr. Joseph Magliocca is a Clinical Instructor, Department of Surgery, University of Wisconsin. Direct correspondence and requests for reprints to Dr. Kelly Magliocca, University of Michigan, Department of Oral \& Maxillofacial Surgery, 1011 N. University, Ann Arbor, MI 48109; 734-764-1548 phone; 734-615-1415 fax; cottrk@hotmail.com.

Key words: obesity, dental students, dental hygiene students, education, attitudes

Submitted for publication 7/7/05; accepted 9/14/05

$\mathrm{O}$ besity has reached epidemic proportions, currently representing the second leading cause of preventable death in this country. ${ }^{1-3}$ It is estimated that 30 percent of the adult population in the United States is obese. ${ }^{1}$ The obese patient often presents with multiple medical problems and treatment challenges, many with implications for the practice of dentistry. While numerous articles have emphasized the importance of expanding obesity education in nursing and medical schools, there is little published literature regarding the integration of obesity education into the dental curricula. Based on the paucity of data in this area, one may hypothesize that dental and dental hygiene students receive relatively little education with regards to obesity. Without formal training, students may fail to recognize the unique needs of the obese patient population. In addition to the numerous medical problems associated with obesity, obese patients are also exposed to public disapproval and negative attitudes that have been documented to exist in education, the workplace, and the mass media as well as in the health care profession. ${ }^{4-7}$ A negative bias was hypothesized to exist among this student (dental and dental hygiene) population based on the presence of negative attitudes that have been found in other health care sectors.

\section{Methods}

A questionnaire used to examine attitudes of physicians toward obesity by Foster et al. ${ }^{7}$ was adapted for this investigation. (Permission for the use and modification of the survey was obtained from the copyright owners.) The University of Michigan Institutional Review Board granted approval for this study and the modified questionnaire.

Study participants included the entire population of dental and dental hygiene students currently enrolled at the University of Michigan School of Dentistry who were present in class on the day of survey distribution. The students were given the anonymous, voluntary, seventeen-item, paper and pencil questionnaire in class, near the completion of the 2005 academic year. The survey was distributed and collected in the same class meeting. If students were absent from class, no effort was made to identify these students or approach them to complete the survey. No demographic information was collected on the study population except whether the respondent was a dental student or a dental hygiene student and their current year of training.

To test the hypothesis that dental and dental hygiene students lack formal obesity education within their respective professional disciplines, the partici- 
pants were asked to respond to a series of questions (Table 1). To assess whether students recognized the scope of their professional duties as well as management issues linked to the unique patient population, students were asked to respond to the questions listed in Table 2. Questions listed in Table 3 were used to detect the presence of bias and negative attitude amongst dental hygiene and dental students. Survey answers were recorded using a Likert-item response with five categories ranging from strongly disagree $=1$ to strongly agree $=5$. A negative attitude was defined as a response of "strongly disagree" or "disagree." A positive attitude was defined as a response of "strongly agree" or "agree." A response of "not sure" was equated with uncertainty or indecision. No validity or reliability testing on the questionnaire was conducted.

Much of the material collected was descriptive in nature. Discrete variables were analyzed using a two-tailed Fisher's exact test or a Chi-squared analysis. A $p$-value $\leq 0.05$ was considered significant.

\section{Results}

The survey was distributed to a group of 464 students consisting of 387 dental students and seventy-seven dental hygiene students. The response rate

\section{Table 1. Knowledge-based obesity questions}

Please circle the total number of hours (didactic/lecture presentations) you feel have been devoted to the topic of obesity since you first began your Dental/Dental Hygiene studies.

0-1 hr 2-5 hrs 6-10 hrs 11-15 hrs

- I have taken other courses prior to dental school that educated me about obesity.

- Obesity is a chronic medical disease.

- Small weight losses (5-10 percent of body weight) can produce important medical benefits for obese patients.

- Obesity is associated with serious medical conditions.

- I can correctly identify the World Health Organization definitions of overweight, obese, and morbidly obese patients.

- I can provide a differential diagnosis list for obesity (i.e., two or three other conditions that mimic obesity).

Scale: $\mathrm{SA}=$ strongly agree, $\mathrm{A}=$ agree, $\mathrm{N}=$ neutral, $\mathrm{D}=$ disagree, $\mathrm{SD}=$ strongly disagree Adapted with permission from Obes Res 2003;11(10):1168-77.

\section{Table 2. Perception of professional responsibility}

- Treating obese patients in dentistry means I will need to make accommodations in equipment and office furniture.

- In my discipline, it is important to assess a patient's dietary habits.

- I would be interested in learning about obesity in dental school.

Scale: $\mathrm{SA}=$ strongly agree, $\mathrm{A}=$ agree, $\mathrm{N}=$ neutral, $\mathrm{D}=$ disagree, $\mathrm{SD}=$ strongly disagree Adapted with permission from Obes Res 2003;11(10):1168-77.

\section{Table 3. Attitudes toward obesity}

- I have negative reactions towards the appearance of obese patients.

- It is difficult for me to feel empathy for an obese patient.

- I feel uncomfortable when examining an obese patient.

- Overweight people tend to be lazier than normal weight people.

- Overweight people lack willpower and lack motivation in comparison to normal weight people.

- I would feel uncomfortable asking an obese patient about his or her dietary habits.

- I would feel uncomfortable asking an obese patient about his or her past use of appetite suppressants or current and past anti-obesity medications.

Scale: $\mathrm{SA}=$ strongly agree, $\mathrm{A}=$ agree, $\mathrm{N}=$ neutral, $\mathrm{D}=$ disagree, $\mathrm{SD}=$ strongly disagree Adapted with permission from Obes Res 2003;11(10):1168-77. 
was 100 percent for dental hygiene students. Fortyfour dental students (11 percent) did not return the survey, for a response rate of 89 percent. There was a significant difference in the response rate between dental hygiene and dental students $(p<0.01)$. A total of 420 students returned the survey for an overall response rate of 91 percent. Since this was an anonymous and voluntary survey, no further demographics were available regarding responders or nonresponders.

\section{Obesity Education}

Dental and dental hygiene students were asked to estimate the total number of hours dedicated to obesity education thus far in their respective professional curricula. Of the 420 surveys returned, 369 students ( 88 percent) provided a response to this question. One hundred and thirty-three (39 percent) dental students and twenty-eight (36 percent) dental hygiene students reported the dedication of one hour or less in the curricula to obesity. One hundred and forty-eight (43 percent) dental students and twentyseven ( 35 percent) dental hygiene students reported receiving between two and five hours of obesity education (Figure 1). The majority of both dental and dental hygiene students reported five hours or less education (281 [92 percent] vs. 55 [85 percent], $p=0.06$ ). When the individual classes (first year, second year, etc.) within the predoctoral dental curricula were compared, there was no significant difference in the number of education hours. There was a difference in self-reported obesity education noted within the dental hygiene classes. All senior dental hygiene students reported less than five hours of education when compared with 58 percent of secondyear dental hygiene students $(\mathrm{p}=0.01)$ and 78 percent of first-year dental hygiene students $(\mathrm{p}=0.3)$.

The responses to the remaining survey items completed by dental hygiene and dental students were assembled into one single group referred to as "students" rather than drawing comparisons between the responses of dental hygiene and dental students. Additionally, it was noted that the remaining questionnaire items had a nonresponder rate of less than 2 percent, which was found to be evenly distributed between the remaining questions.

Participants were asked if they had received obesity education during their undergraduate preparatory coursework, prior to beginning professional studies in dentistry. Over half (51 percent) of the students reported that they had not had any prior obe-

\section{Self-Reported Hours of Obesity Education}

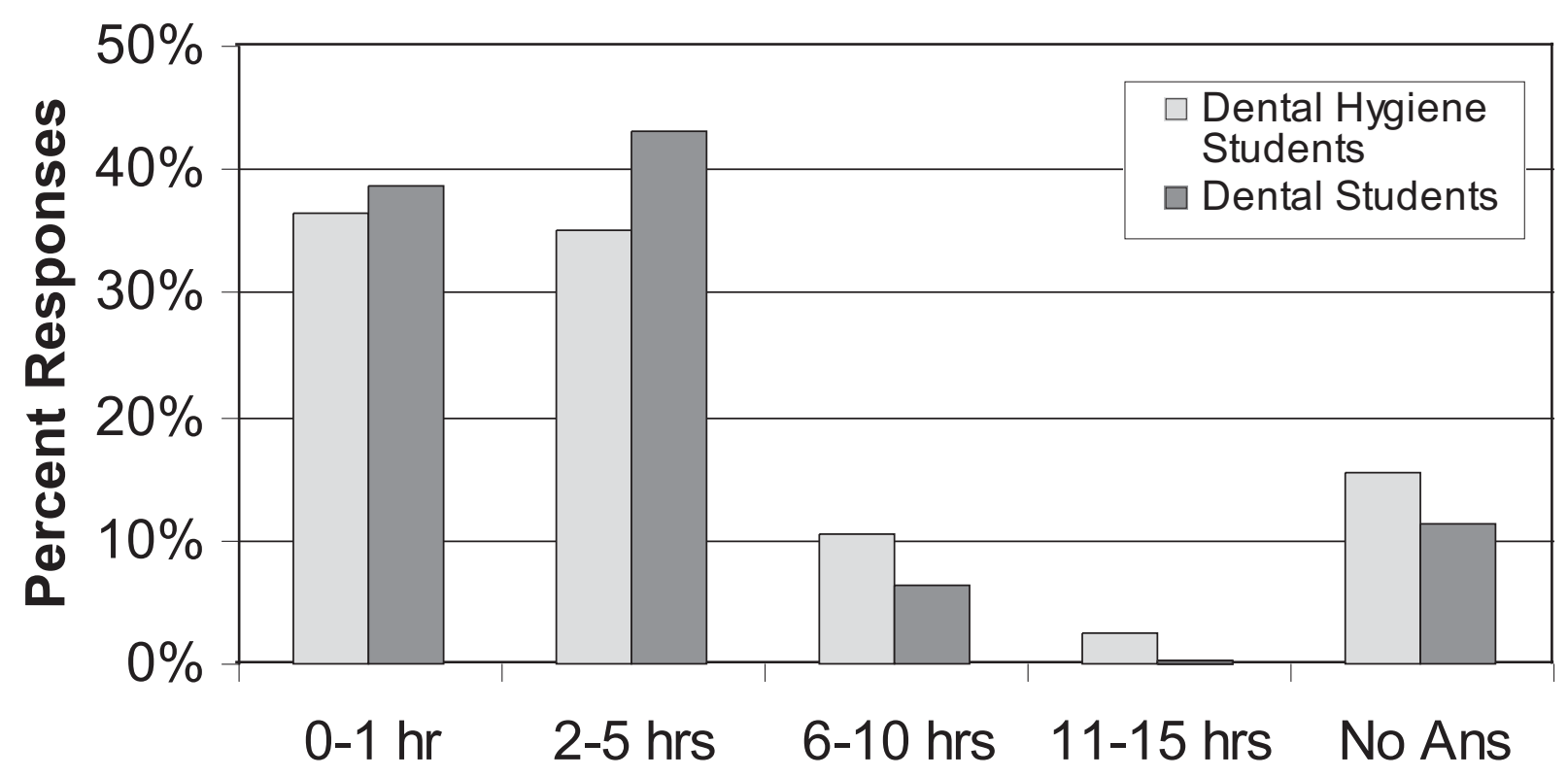

Figure 1. Students' perception of hours of obesity education experienced during the dental or dental hygiene curriculum 
sity education; 153 (37 percent) indicated they had received some prior obesity education; and 13 percent were unsure. When asked if obesity was a chronic disease, a large percentage of the students (80 percent) agreed, while fifty-seven (14 percent) were uncertain and twenty-six (6 percent) disagreed. Students were asked to respond to the statement: "Small weight losses of 5-10 percent of body weight can produce important medical benefits for obese patients." A large percentage of participants (84 percent) concurred, while fifty-nine (14 percent) were unsure and ten ( 2 percent) disagreed. Ninety-four percent of respondents were aware of an association between obesity and serious medical conditions, while eighteen ( 4 percent) expressed uncertainty and six (1 percent) were unaware of such an association. Students were asked to indicate their ability to successfully identify the World Health Organization (WHO) classification for obesity. Forty-three percent of students lacked confidence in their ability to provide a correct classification, but 141 students (34 percent) predicted they could successfully stratify patients according to the WHO classification, based on body mass index. When participants were asked if they could provide a differential diagnosis for obesity, 160 students (38 percent) felt that they could provide a differential diagnosis, 133 (32 percent) were uncertain, and 126 (30 percent) reported that they were unable to do so.

\section{Professional Obligations}

Students were asked a series of questions about their attitudes and expectations regarding treating obese patients. When participants were asked if the treatment of an obese patient in a dental office setting would require special equipment or other accommodations, 270 students (65 percent) concurred. One hundred (24 percent) students were undecided, and forty-seven (11 percent) did not perceive any office modification would be required. Students were asked to respond to the statement: "In my discipline, it is important to assess a patient's dietary habits." Four hundred and two students (96 percent) believed that it was important for oral health practitioners to assess a patient's dietary habits.

Students were questioned about their level of interest in augmenting the professional curricula with additional obesity education. Two hundred and seventy-nine students (67 percent) were in favor of this addition, ninety (22 percent) were undecided, and a minority (12 percent) conveyed their lack of inter- est. A comparison of the amount of preprofessional obesity education between these three categories of students (interested, undecided, not interested) was accomplished to ascertain whether or not students felt that they had already accumulated sufficient training, obviating additional studies. Of the 279 students who were interested in obesity education in dental school, 227 ( 81 percent) had $\leq 5$ hours of preprofessional education on obesity and twenty-three ( 8 percent) had $>5$ hours. Ninety students were neutral with regards to further dental obesity education: seventy-six ( 84 percent) had $\leq 5$ hours of education, and four (4 percent) had $>5$ hours. Of the students who expressed no interest, thirty-three (67 percent) had $\leq 5$ hours education, and five (10 percent) had $>5$ hours. When comparing the number of students who were interested in further obesity education in dental school with those who were neutral or not interested, there was no difference in the number of students who already had $>5$ hours of preprofessional obesity education ( 23 vs. $9, p=0.6$ ).

\section{Attitudinal Items}

Students were asked if they experience a negative reaction to the appearance of an obese patient. Less than half of the students (48 percent) denied this reaction. One hundred thirty students (31 percent) acknowledged feeling a negative reaction toward the appearance of obese patients while eighty-six (21 percent) were neutral. Students were asked to respond to the statement: "It is difficult for me to feel empathy for an obese patient." The majority of students (272; 66 percent) reported that it was not difficult to feel empathy for an obese patient; however, seventy-one (17 percent) did consider it difficult, and seventy (17 percent) were unsure. When participants were asked if they felt uncomfortable examining an obese patient, 284 (68 percent) were not, while seventy-four (18 percent) were neutral and sixty (14 percent) were uncomfortable. When asked if overweight people are lazier than normal weight people, 167 (40 percent) disagreed with the question. One hundred twenty-five students ( 30 percent) felt that overweight people are lazier than their non-obese counterparts, while 126 (30 percent) were neutral.

When students were asked, "Do you feel that overweight people lack willpower and motivation in comparison to normal weight people?," 199 (47 percent) disagreed. One hundred ten students (26 percent) felt that overweight people do lack willpower and motivation compared with their non-obese coun- 
terparts, while 110 (26 percent) were uncertain. Participants also indicated their level of comfort in exploring the dietary habits of obese patients. The majority of students (52 percent) were comfortable in doing so, while 129 students (31 percent) were uncomfortable and the remainder (18 percent) were uncertain. Students indicated their level of comfort in questioning a patient about a prior history of appetite suppressant use. The majority of students (252; 60 percent) reported feeling comfortable asking obese patients about their past use of appetite suppressant medications, eighty-seven students (21 percent) felt uncomfortable, and eighty (19 percent) were unsure about their comfort level.

\section{Discussion}

The health problems that accompany obesity have gained much attention..$^{1,3,8-10}$ Many of these comorbidities have consequences for oral health professionals in the course of patient care, yet few studies emphasize the relevance of obesity to dentistry. Obesity can directly impact dental treatment and oral health via the negative effect on the periodontium ${ }^{11,12}$ and xerostomia through the effects of polypharmacy ${ }^{13}$ and may negatively influence the safety of adjunctive intravenous sedation ${ }^{14}$ or increase the level of difficulty in achieving regional anesthetic blockade. ${ }^{15}$ Additionally, the comorbidities commonly associated with obesity, such as diabetes mellitus, ${ }^{16}$ cerebrovascular disease, ${ }^{17}$ heart disease, ${ }^{18}$ hypertension,,${ }^{19}$ depression, ${ }^{13}$ oteoarthritis, ${ }^{20}$ asthma, ${ }^{21}$ and obstructive sleep apnea ${ }^{22}$ have also been described to influence dental treatment. Obesity itself is not related to increased rates of oral cancer, but it is associated with an increased incidence of other cancers, many of which have been shown to metastasize to the jaws. ${ }^{23}$

The results of this survey found that over half of students reported no formal education regarding obesity prior to beginning dental and dental hygiene studies (professional education). The data presented in Figure 1 appear to show that almost 40 percent of dental students and over 35 percent of dental hygiene students reported the dedication of one hour or less in the curricula to obesity. A similar proportion reported experiencing between two and five hours in the professional curricula. One may speculate that the difference in self-reported education occurred as a result of curriculum changes in this cross-sectional representation of students or, alternatively, as a re- sult of the students simply forgetting learned information over time. However, if the estimate on the number of hours of obesity education is accurate, the deficiency in education is troubling, given that the obesity epidemic is a worldwide problem. Obesity or related coursework prior to entering professional education was minimal for most students, and it was not surprising that most students were interested in learning more about obesity. Less than 40 percent of the participants were confident in their ability to define the WHO classification for obesity. Understanding the classification of obesity is important to properly interpret the literature but is crucial to fully appreciate the spectrum of comorbidities that tend to increase in prevalence with the severity of obesity. ${ }^{9,10,24,25}$

In 1985, the National Institutes of Health consensus conference recognized obesity as a chronic disease. ${ }^{26}$ Despite the limited formal education for most students, 80 percent understood obesity to be a chronic disease, and 94 percent were aware of the association of obesity with serious medical conditions. Not only does the recognition of obesity as a serious disease enable patients to obtain appropriate medications and treatments; it should facilitate the public's attainment of a greater sense of acceptance of obesity and reduce bias and stigmatization. ${ }^{27,28}$ While the features of obesity may appear obvious, the diagnosis may not be straightforward. Less than 40 percent of students could confidently provide a differential diagnosis for an obese patient. Hypothyroidism, pituitary disease, and other endocrine disorders, as well as mass lesions such as polycystic kidney disease or malignancy, may masquerade as "primary" obesity ${ }^{25,29}$ Additionally, certain medications can cause significant weight gain resulting in "secondary" obesity. ${ }^{30}$

Eighty-four percent of respondents agreed that even small weight losses were medically important. Evidence suggests that weight losses of 5-10 percent may lead to a decrease in medication requirements for diabetes mellitus and hypertension in addition to other health benefits. ${ }^{8,9,24,31}$ It is certainly possible that mass media coverage of obesity and its associated medical concerns has at least provided a basic concept of the significance of obesity and the benefits of weight loss.

The results suggest that almost 35 percent of students did not recognize or were unsure if the treatment of obese patients in an office setting would require equipment modifications or special accommo- 
dations. Data from the medical literature advise practitioners to at least consider armless waiting room chairs, armless treatment chairs, and oversized blood pressure cuffs. ${ }^{32}$ Using a standard size blood pressure cuff on a large arm will falsely elevate the blood pressure reading. ${ }^{33}$ Having appropriately sized equipment avoids practical problems during treatment, but may also reduce a sense of stigmatization toward an obese patient in the dental office.

A thorough review of a patient's past medical and dental history is essential in order to conduct safe and effective treatment. The present findings indicate that only 60 percent of students felt comfortable asking an obese patient about their past use of appetite suppressant medications. One potential explanation for this lies in the lack of understanding of the significance of prior use of particular prescription appetite suppressants and the association with valvular heart disease..$^{34,35}$ In 1997, the makers of fenfluramine and dexfenfluramine voluntarily withdrew these drugs from the market after data reported to the U.S. Food and Drug Administration demonstrated an increased prevalence of cardiac valvular lesions in up to 30 percent of asymptomatic patients using either of these diet drugs alone or in combination with other drugs. ${ }^{34}$ Since that discovery, some cardiac lesions have regressed and others remain unchanged, while others have deteriorated. ${ }^{36}$ Four hundred and two students (96 percent) recognized the importance of assessing patients' dietary habits within the scope of their respective practices. Unfortunately, 129 students (31 percent) were uncomfortable asking obese patients about their dietary habits. Through didactic and observational learning in dental education, this discomfort must be replaced with ease of conversation. The information regarding nutrition and diet can and must be obtained professionally and in a nonjudgmental fashion because a diet history is necessary in treatment planning as well as prevention of oral disease. ${ }^{37,38}$

When examining the data regarding negative attitudes towards obese patients within our study cohort, results were similar to data seen in other professional fields. ${ }^{4,6,7}$ Approximately 30 percent of students felt that overweight people are lazier than nonobese people, and an equal number of students expressed uncertainty about the statement. Over 26 percent of students felt that overweight people lack willpower and motivation when compared with their non-obese counterparts, and an equal percentage of students were neutral. It has been said that obese people are the "last acceptable targets of discrimination. ${ }^{39,40}$ Dental educators must make it a priority to discuss obesity, disseminate factual knowledge, and discuss stereotypes and biases that exist against corpulent patients. Over 30 percent of students reported a negative reaction to the appearance of obese patients, and 14 percent were uncomfortable in examining an obese patient, similar to the data found in other health care sectors. ${ }^{7}$ Obesity is a chronic medical disease, similar to a disease state such as hypertension or diabetes mellitus, ${ }^{8}$ yet 17 percent of students considered it difficult to feel empathy for an obese patient. Many potential explanations for the negative attitudes exist. They may result from preexisting attitudes, possible observation of negative behaviors by clinical instructors, colleagues, and support staff, or perhaps a lack of specific education about the multifactorial etiology of obesity.

Several limitations of the study are recognized. The study participants represent the use of a convenience sample at one academic institution at a single point in time. The attitudes, perception of education, and beliefs about professional duties that we found are not necessarily representative of all dental and dental hygiene students across the country and may be subject to selection or institutional biases. The presence of survey bias, responder bias, intentional deception on the part of the respondents, poor memory, and misunderstanding of the questions may also have affected survey results. Additionally, the number of hours devoted to obesity education, both undergraduate and professional, represents a selfreported estimate. Neither the content nor the actual number of hours of obesity education is known and may be impossible to ascertain since each instructor directs student discussions as he or she sees fit. Determining a true representation of content and number of hours represents an interesting point for future investigation.

During the analysis of the students' responses, it was noted that approximately 12 percent of respondents neglected to answer one specific question regarding the number of hours of obesity education accumulated since entering professional education. It is believed that this was likely due to the layout of the survey since this particular item was positioned outside the boundaries of the survey table. Students may have assumed that the question was part of the study preamble and proceeded directly to survey items within the boundaries of the table. With respect to blank responses within the survey proper, it 
was noted that unanswered questions were evenly distributed throughout the questions and the prevalence was found to be less than 2 percent for any individual survey question. While it is possible that unanswered questions actually represented strong opinions that students felt uncomfortable expressing given the nature of the survey, even if all of the individual blank questions represented strong, "unpopular" answers, the effect on the survey outcome would have been negligible.

Combining the dental hygiene and dental students allowed us to survey a greater number of students but may have potentially influenced a number of variables. Currently in this particular dental institution, the majority of dental hygiene students are female, which may have introduced gender bias into the responses. To avoid comparing mostly female responses of hygiene students against an unknown gender distribution of dental students, the two groups were combined.

Demographic data such as age, weight, gender, or race/ethnicity were not collected from the study participants. The survey was purposely structured in this way in an effort to offer the participants additional anonymity and, hopefully, to reduce the number of false, "non-offensive" responses. Thus, it is impossible to define the demographics of the responders or, of equal importance, of the nonresponders. It is not known which groups, if any, were over- or underrepresented. One may hypothesize that overweight students or students with overweight or obese family members would express less attitudinal bias due to their own personal experience or sensitivity to the subject-yet another interesting area for future research. Despite this study design, some students may have intentionally responded in a "non-offensive" manner given the nature of the topic. This could potentially result in an underestimation of any negative attitudes that may exist. Perhaps most importantly, it is impossible to infer a causal relationship between the lack of obesity education and the presence of a negative attitude towards an obese patient.

The survey was not reviewed or pilot-tested by dental or dental hygiene students at any level. Thus, it is unknown if the administration of the same survey to various dental hygiene or dental classes is appropriate. With respect to those students disclosing a lack of education about obesity, the validity of their responses to queries regarding attitudes, experience, or perceptions about obesity is not known. Moreover, some students reported having specific knowledge of obesity (the classification, ability to provide a differential diagnosis for obesity, etc.), but the accuracy of the responses was not confirmed. Given these limitations, generalizations should be made with caution.

\section{Conclusions}

Much work is yet to be done within dental education and dentistry in general regarding obesity. This cross-sectional survey study represents the first work of its kind in assessing knowledge, beliefs, and attitudes about obesity within a group of dental and dental hygiene students. Given that obesity is a substantial public health concern and has significant treatment implications in dentistry, obesity education should be integrated into the curricula of dental and dental hygiene students. Discussing weight is likely to be a straightforward charge, since oral health care practitioners routinely emphasize prevention and lifestyle changes, in addition to health and wellness behaviors. The blueprints that have been developed to discuss oral health in terms of the use of sports mouth guards, dietary modifications, and smoking cessation can be modified to suit a discussion of healthy weight. One of the major obstacles reported to smoking cessation is the fear of weight gain, ${ }^{41}$ but little data is available on how smoking cessation programs based in dentistry address a patient's concerns about this issue.

Integration of obesity education into the professional dental and dental hygiene training would provide salient information and augment the informed discussion regarding the risks and benefits of weight gain versus smoking cessation. It is time to initiate the discussion of obesity and overweight in professional dental and dental hygiene education to enable safe, unbiased oral health care.

\section{Acknowledgment}

The authors wish to acknowledge the support and encouragement of Joseph I. Helman, D.M.D.

\section{REFERENCES}

1. Flegal KM, Carroll MD, Ogden CL, Johnson CL. Prevalence and trends in obesity among US adults, 1999-2000. JAMA 2002;288:1723-7.

2. Mokdad AH, Ford ES, Bowman BA, Dietz WH, Vinicor F, Bales VS, et al. Prevalence of obesity, diabetes, and obesity-related health risk factors, 2001. JAMA 2003;289:76-9. 
3. Mokdad AH, Marks JS, Stroup DF, Gerberding JL. Actual causes of death in the United States, 2000. JAMA 2004;291:1238-45.

4. Cossrow NH, Jeffery RW, McGuire MT. Understanding weight stigmatization: a focus group study. J Nutr Educ 2001;33:208-14.

5. Hebl MR, Xu J. Weighing the care: physicians' reactions to the size of a patient. Int J Obes Relat Metab Disord 2001;25:1246-52.

6. Puhl RM, Brownell KD. Psychosocial origins of obesity stigma: toward changing a powerful and pervasive bias. Obes Rev 2003;4:213-27.

7. Foster GD, Wadden TA, Makris AP, Davidson D, Sanderson RS, Allison DB, et al. Primary care physicians' attitudes about obesity and its treatment. Obes Res 2003;11:1168-77.

8. Bray GA. Medical consequences of obesity. J Clin Endocrinol Metab 2004;89:2583-9.

9. Obesity: preventing and managing the global epidemicreport of a WHO consultation. World Health Organ Tech Rep Ser 2000;894:i-xii, 1-253.

10. Eliasson M, Lindahl B, Lundberg V, Stegmayr B. Diabetes and obesity in Northern Sweden: occurrence and risk factors for stroke and myocardial infarction. Scand J Public Health Suppl 2003;61:70-7.

11. Saito T, Shimazaki Y, Kiyohara Y, Kato I, Kubo M, Iida $\mathrm{M}$, et al. Relationship between obesity, glucose tolerance, and periodontal disease in Japanese women: the Hisayama study. J Periodontal Res 2005;40:346-53.

12. Al-Zahrani MS, Bissada NF, Borawskit EA. Obesity and periodontal disease in young, middle-aged, and older adults. J Periodontol 2003;74:610-5.

13. Friedlander AH, Mahler ME. Major depressive disorder: psychopathology, medical management and dental implications. J Am Dent Assoc 2001;132:629-38.

14. Todd DW. Anesthetic considerations for the obese and morbidly obese oral and maxillofacial surgery patient. J Oral Maxillofac Surg 2005;63:1348-53.

15. Nielsen KC, Guller U, Steele SM, Klein SM, Greengrass RA, Pietrobon R. Influence of obesity on surgical regional anesthesia in the ambulatory setting: an analysis of 9,038 blocks. Anesthesiology 2005;102:181-7.

16. Muhammad S. Epidemiology of diabetes and obesity in the United States. Compend Contin Educ Dent 2004; 25:195-8, 200, 202; quiz 204.

17. Cohen SN, Friedlander AH, Jolly DA, Date L. Carotid calcification on panoramic radiographs: an important marker for vascular risk. Oral Surg Oral Med Oral Pathol Oral Radiol Endod 2002;94:510-4.

18. Paquette DW. The periodontal-cardiovascular link. Compend Contin Educ Dent 2004;25:681-2, 685-92.

19. Little JW. The impact on dentistry of recent advances in the management of hypertension. Oral Surg Oral Med Oral Pathol Oral Radiol Endod 2000;90:591-9.

20. Antibiotic prophylaxis for dental patients with total joint replacements. J Am Dent Assoc 2003;134:895-9.

21. Steinbacher DM, Glick M. The dental patient with asthma: an update and oral health considerations. J Am Dent Assoc 2001;132:1229-39.
22. Magliocca K, Helman JI. Obstructive sleep apnea: diagnosis, medical management and dental implications. J Am Dent Assoc 2005;136:1121-9.

23. van der Waal RI, Buter J, van der Waal I. Oral metastases: report of 24 cases. Br J Oral Maxillofac Surg 2003;41:3-6.

24. Dixon JB, Dixon ME, O'Brien PE. Depression in association with severe obesity: changes with weight loss. Arch Intern Med 2003;163:2058-65.

25. Bray GA, Ryan DH. Clinical evaluation of the overweight patient. Endocrine 2000;13:167-86.

26. Health implications of obesity. National Institutes of Health Consensus Development Conference Statement. Ann Intern Med 1985;103:147-51.

27. Bray GA. Obesity is a chronic, relapsing neurochemical disease. Int J Obes Relat Metab Disord 2004;28:34-8.

28. Dausch J. Determining when obesity is a disease. J Am Diet Assoc 2001;101:293.

29. Kushner RF, Roth JL. Assessment of the obese patient. Endocrinol Metab Clin North Am 2003;32:915-33.

30. Devlin MJ, Yanovski SZ, Wilson GT. Obesity: what mental health professionals need to know. Am J Psychiatry 2000;157:854-66.

31. Goldstein DJ. Beneficial health effects of modest weight loss. Int J Obes Relat Metab Disord 1992;16:397-415.

32. Hill JO, Wyatt H. Outpatient management of obesity: a primary care perspective. Obes Res 2002;10(Suppl 2):124S-130S

33. Fonseca-Reyes S, de Alba-Garcia JG, Parra-Carrillo JZ, Paczka-Zapata JA. Effect of standard cuff on blood pressure readings in patients with obese arms. How frequent are arms of a "large circumference"? Blood Press Monit 2003;8:101-6.

34. Volmar KE, Hutchins GM. Aortic and mitral fenfluraminephentermine valvulopathy in 64 patients treated with anorectic agents. Arch Pathol Lab Med 2001;125:1555-61.

35. Bonow RO, Carabello B, de Leon AC Jr., Edmunds LH Jr., Fedderly BJ, Freed MD, et al. Guidelines for the management of patients with valvular heart disease: executive summary. A report of the American College of Cardiology/American Heart Association Task Force on Practice Guidelines (Committee on Management of Patients with Valvular Heart Disease). Circulation 1998;98:1949-84.

36. Gardin JM, Weissman NJ, Leung C, Panza JA, Fernicola $\mathrm{D}$, Davis KD, et al. Clinical and echocardiographic follow-up of patients previously treated with dexfenfluramine or phentermine/fenfluramine. JAMA 2001;286:2011-4.

37. Touger-Decker R, Mobley CC. Position of the American Dietetic Association: oral health and nutrition. J Am Diet Assoc 2003;103:615-25.

38. Touger-Decker R. Role of nutrition in the dental practice. Quintessence Int 2004;35:67-70.

39. Puhl R, Brownell KD. Bias, discrimination, and obesity. Obes Res 2001;9:788-805.

40. Stunkard AJ, Sorensen TI. Obesity and socioeconomic status: a complex relation. N Engl J Med 1993;329:1036-7.

41. Filozof C, Fernandez Pinilla MC, Fernandez-Cruz A. Smoking cessation and weight gain. Obes Rev 2004;5: 95-103. 